\title{
Describing the process of ethical conduct of research in an Ontario-wide First Nations diabetes research project
}

\author{
Jennifer D. Walker PhD, Robyn Rowe MA, Carmen R. Jones BA
}

- Cite as: CMAJ 2018;190(Suppl 1):S19-S20. doi: 10.1503/cmaj.180479

(

$\mathrm{n}$ recent decades, diabetes and related complications have emerged as substantial challenges in First Nations communities in Canada. ${ }^{1}$ To advocate for appropriate services within a complex, and often fragmented, health system for First Nations people, ${ }^{2,3}$ First Nations leaders need access to population-level data. Recent data-linkage initiatives have provided an opportunity for First Nations-led population studies of diabetes and its effects that were not previously possible. We designed a study (Reducing the Burden of Diabetes on First Nations People in Ontario: Using Population Level Data to Improve Policy and Practice) as one of the first opportunities for First Nations in Ontario to plan collectively and implement an Ontario-wide study to support the diabetes-related information needs of First Nations leadership, government and community workers, and involve patients, Elders, leadership and community members in ways appropriate to the First Nations context.

One of the defining aspects of our study was the partnership between academic researchers and the Chiefs of Ontario, which has a mandate to advocate on behalf of the 133 First Nations in Ontario. The academic research team, senior health staff from the Chiefs of Ontario, an Elder and two First Nations patient navigators co-developed the research proposal. These early collaborations allowed the team to establish processes for working together, formalized in a research agreement, and to set research questions. The research objectives were to describe First Nations-specific rates of diabetes and its complications over 20 years, on- and offreserve, and for different geographic regions; to understand access to diabetes-related screening, management and treatment of complications; and to assess the impact of limits on blood glucose testing strips that were set by changes in federal and provincial policy.

To do this, we analyzed administrative health data held at ICES that are governed by First Nations in Ontario. ${ }^{4}$ In parallel, we worked with five First Nations communities to undertake interviews with people living with diabetes and health care professionals. Data from these interviews were used to contextualize and better understand patient encounters with the health care system and the trajectories of care experienced by First Nations people with diabetes. The culmination of this work is a comprehensive First Nations Diabetes Report (forthcoming in February 2019 and

\section{KEY POINTS}

- Our approach to patient-oriented First Nations research integrated knowledge from patient and community experiences, policyrelated information, clinical and methodological knowledge, and First Nations perspectives through involvement of First Nations patients, researchers, care providers and Elders.

- Patient-oriented research in the context of First Nations health research requires a collaborative co-leadership approach that integrates community-based participatory research approaches and First Nations principles of ownership, control, access and possession of data and information (OCAP).

- Dedicated research positions to support patient and community engagement were essential to the meaningful participation of patients and First Nations communities.

- A key impact of our collaborative and patient-engaged approach has been to acknowledge the complexity of the causes and implications of diabetes in First Nations individuals and to promote strength-based interventions.

to be released at the Chiefs of Ontario First Nations Health Research Symposium) that considers the contextual roots underlying high rates of diabetes.

Our approach to patient-oriented research was multilayered; members of the research team were also First Nations people with diabetes or family members of people with diabetes. We also established a six-member patient advisory group of First Nations individuals with lived experience with type 2 diabetes to work with us throughout all subsequent phases of the research project. Advisory group members were selected to provide a range of perspectives, and included men and women, Elders and youth, and individuals from various geographic regions. To select these patient advisors, we worked with the Health Coordination Unit (the unit is supported by the Chiefs of Ontario and includes members from various First Nations organizations across Ontario), which includes health directors who coordinate the interests of First Nations communities, to ensure that we involved patients with diabetes who are from diverse First Nations communities in Ontario. The advisory group met about twice per year and provided critical input 
into our approaches, qualitative interview questions, analysis and interpretation of both qualitative and quantitative data, and important context that informed the way we presented and shared the knowledge from the project.

We also prioritized community-level involvement, and our project was informed by community-based participatory research approaches ${ }^{5}$ and principles of Indigenous data sovereignty, ${ }^{4,6}$ notably First Nations' ownership, control, access and possession of First Nations data and information (OCAP). ${ }^{7}$ The Health Coordination Unit provided input to ensure that we were conducting the project in ways that aligned with First Nations governance approaches and priorities. For example, they guided the team to include five communities for the qualitative component instead of four, to align with the structure of the 133 First Nations and their affiliations to Provincial Territorial Organizations, and the members worked with us to invite communities to participate. Once the individual communities were determined, we worked closely with each one to obtain permission for the project and conduct the interviews in ways that were specific to that community. We attended community meetings and fairs to share information with community members.

In a parallel but distinct process to First Nations community and patient involvement, First Nations research often also requires permission and approvals. The overall project served as the pilot application to the newly created First Nations Data Governance Committee that was appointed by the Ontario Chiefs Committee on Health to oversee researcher requests to access the First Nations data at ICES. This written application addressed the ways in which the project respected First Nations principles and provided benefits to First Nations. As the pilot application, we provided feedback on the process to refine modifications for future applications.

Applying patient-oriented research approaches is a natural extension of strong community-based approaches that are integral to the ethical conduct of First Nations health research. One of the key features of this work was the need to involve four distinct groups: Elders, First Nations coordination and advocacy organizations, individual patients and academic partners. We engaged Elders throughout the process as members of the patient advisory group, in communities and on the project team. We found that having more than one way to involve Elders was helpful and that monthly project meetings were too frequent to maintain consistent and meaningful involvement of a single person.

We used a portion of our funding to hire a full-time integrated knowledge broker at the Chiefs of Ontario who speaks a First Nations language, which is important for understanding First Nations perspectives. The individual provided ongoing integrated knowledge translation and support for the relationships with Elders, the patient advisory group, the Health Coordination Unit and external partners.

The research team had identified a need to engage with other Indigenous organizations that support the well-being of First Nations people living in cities. These efforts involved several introductory discussions initiated by the academic research team, but did not progress to meaningful involvement. This was a challenging undertaking because research collaborations between the urban Indigenous organizations and the First Nations organizations involved in the project are not yet established and will take time to build.

In summary, our First Nations-led research addressed important gaps where data are needed to improve decisionmaking and advocacy. A key impact of our collaborative approach has been to acknowledge the complexity of the causes and context for diabetes in First Nations communities and to promote strength-based interventions. This project supported the use of First Nations-identified health administrative data, which is critical to the processes of self-determination and healing for First Nations communities in Ontario.

\section{References}

1. Jacklin KM, Henderson RI, Green ME, et al. Health care experiences of Indigenous people living with type 2 diabetes in Canada. CMAJ 2017;189:E106-12.

2. Cummins S, Curtis S, Diez-Roux AV, et al. Understanding and representing 'place' in health research: a relational approach. Soc Sci Med 2007;65:1825-38.

3. Fitzpatrick SJ, Perkins D, Luland T, et al. The effect of context in rural mental health care: Understanding integrated services in a small town. Health Place 2017;45:70-6.

4. Walker J, Lovett R, Kukutai T, et al. Indigenous health data and the path to healing. Lancet 2017;390:2022-3.

5. Cargo M, Mercer SL. The value and challenges of participatory research: strengthening its practice. Annu Rev Public Health 2008;29:325-50.

6. United Nations declaration on the rights of Indigenous Peoples. New York: United Nations; 2008. Available: www.un.org/esa/socdev/unpfii/documents/DRIPS_en.pdf (accessed 2018 Sept. 8).

7. First Nations Information Governance Centre. The First Nations principles of OCAP. Available: https://fnigc.ca/ocapr.html (accessed 2018 Mar. 29).
More information on this project is available at www.ossu.ca/IMPACTAwards.

Competing interests: Jennifer Walker, Robyn Rowe and Carmen Jones report a grant from OSSU (the Ontario SPOR [Strategy for PatientOriented Research] SUPPORT [Support for People and Patient-Oriented Research and Trials] Unit).

This article was solicited and has been peer reviewed.

Affiliations: School of Rural and Northern Health (Walker, Rowe), Laurentian University, Sudbury, Ont.; Chiefs of Ontario (Jones), Toronto, Ont.

Contributors: Jennifer Walker and Carmen
Jones conceptualized the commentary. Jennifer Walker and Robyn Rowe prepared an initial draft, and all authors contributed to revising the article critically for important intellectual content. All authors have given final approval of the version to be published and agreed to be accountable for all aspects of the work.

Funding: This project was funded by OSSU. The funder did not play a role in the conduct of the project.

Acknowledgements: The authors acknowledge the substantial contributions of Michael Green (nominated principal investigator for the study), Kristen Jacklin (co-principal investigator) and Roseanne Sutherland (integrated knowledge broker), who contributed to revising and reviewing this commentary. The authors also acknowledge the involvement and contributions of the members of the patient advisory group, the other members of the research team (Baiju Shah, Eliot Frymire, Shahriar Khan, Bernadette deGonzague, Linda Ogilvie, Tracy Antone, Shirley Williams, Graham Mecredy, Emily King, Alexander Yurkiewich), collaborating ICES scientists and analysts, and the research assistants and community contacts in each of the five communities that participated in the qualitative component of this study.

Correspondence to: Jennifer Walker, jenniferwalker@laurentian.ca 